\title{
Culture et changement urbain dans les Quartiers Sud de Buenos Aires (Argentine) : des arènes ambiguës
}

Culture and urban change in the Southern Neighborhoods of Buenos Aires (Argentina): ambiguous arenas

Cultura y cambio urbano en los Barrios al Sur de Buenos Aires (Argentina): arenas ambiguas

\section{Barbara Morovich}

\section{OpenEdition}

Journals

Édition électronique

URL : https://journals.openedition.org/ideas/10218

DOI : 10.4000/ideas. 10218

ISSN : $1950-5701$

Éditeur

Institut des Amériques

Référence électronique

Barbara Morovich, « Culture et changement urbain dans les Quartiers Sud de Buenos Aires

(Argentine) : des arènes ambiguës », IdeAs [En ligne], 17 | 2021, mis en ligne le 01 mars 2021, consulté le 05 juin 2021. URL : http://journals.openedition.org/ideas/10218; DOI : https://doi.org/10.4000/ ideas. 10218

Ce document a été généré automatiquement le 5 juin 2021

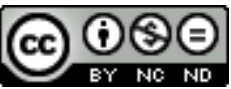

IdeAs - Idées d'Amériques est mis à disposition selon les termes de la licence Creative Commons Attribution - Pas d'Utilisation Commerciale - Pas de Modification 4.0 International. 


\title{
Culture et changement urbain dans les Quartiers Sud de Buenos Aires (Argentine) : des arènes ambiguës
}

\author{
Culture and urban change in the Southern Neighborhoods of Buenos Aires \\ (Argentina): ambiguous arenas \\ Cultura y cambio urbano en los Barrios al Sur de Buenos Aires (Argentina): \\ arenas ambiguas
}

Barbara Morovich

\section{Introduction}

Les usages de la «culture » dans la ville interrogent les sciences sociales ${ }^{1}$. La notion est historiquement au cœur de ces disciplines, et plus particulièrement de l'anthropologie qui depuis sa naissance, s'est employée à définir la « culture » et ses changements (voir dernièrement à ce sujet Rozenberg G., 2020). Déjà les travaux classiques de l'école de Chicago et de l'école de Manchester montraient que la ville est le lieu du changement et des adaptations culturelles des groupes nouvellement arrivés : les cultures façonnaient les villes et vice-versa, dans des interactions avec des choix politiques. Depuis les années 1960, des grandes institutions internationales, comme l'UNESCO, ont produit un glissement du sens de la culture et de ses usages : le « développement culturel » s'est constitué en système légitimant l'action des États dans le secteur culturel et la culture est devenue une catégorie d'action publique à part entière (Bustamante M., 2015 : 156-173). Cette institutionnalisation de la culture est parallèle à la variété des déclinaisons culturelles selon les acteurs (associations, collectifs, groupes politiques, etc.). En tant qu'élément de l'identité, la culture est appropriée par des acteurs selon leurs intérêts réciproques, en lien ou pas avec des politiques culturelles. La sphère culturelle aurait, à l'époque de l'actuelle mondialisation, une place significative, 
s'intégrant parfaitement au marché et justifiant l'usage de l'expression « hypercapitalisme culturel » (Rifkin J., 2000).

2 Dans cet article, j'affirme que l'ambiguïté du mot «culture » et de ses usages est à l'origine du déploiement d'arènes culturelles dynamiques: le mot arène renvoie à un espace de relations et de confrontation d'enjeux pluriels, où « des groupes stratégiques hétérogènes s'affrontent, mus par des intérêts (matériels ou symboliques) plus ou moins compatibles» (Olivier De Sardan J.-P., 1993 : 13). Ces arènes culturelles sont ambiguës car, avant la stabilisation d'un processus patrimonial, elles sont à l'origine de patrimonialisations incertaines (Guinard P. et Morovich B. 2017: 121-145) dans lesquelles les rôles, notamment des artistes, ne sont pas figés et la relation avec les politiques urbaines et les institutions peuvent évoluer par rapport à des intérêts qui surgissent dans le long terme, pouvant aller du compromis à la revendication, jusqu'à l'opposition. Ces arènes se développent en ville, où la culture et le patrimoine sont en lien avec deux phénomènes reliés entre eux : d'un côté la métropolisation et de l'autre la concurrence interurbaine (Djament-Tran G. et San Marco Ph., 2014). La culture se trouve donc au croisement de politiques urbaines qui s'en servent comme catalyseur de changements importants et de la fabrication identitaire de groupes qui élaborent, euxaussi, des projets et des actions culturelles "par la base ». Cependant, afin d'éviter la dichotomisation d'une ville "par le haut » contre une autre "par le bas », le concept d'arène culturelle permet de percevoir des dialogues, des enjeux partiellement communs ou des accords éventuels dans le temps long. A la suite d'auteurs comme Elsa Vivant (2009) ayant critiqué la vision trop réductrice de la classe " créative " (Florida R., 2005), je soutiens que l'impact de la culture dans des espaces urbains est le fruit de négociations complexes avec les institutions, de luttes qui opposent des conceptions différentes, mais parfois compatibles, de la culture. On peut se demander aussi dans quelle mesure des politiques urbaines et culturelles ont des conséquences sur les pratiques et les représentations de celles et ceux qui la conçoivent mais aussi de celles et ceux qui habitent la ville au quotidien. Et comment les groupes répondent ou participent à ces projets.

3 Cet article questionne donc les usages polyvalents de la culture à Buenos Aires, à travers l'exemple des Quartiers Sud qui subissent d'importants processus de changement urbain. Depuis 2008, l'implantation de clusters ou « districts » créatifs ou économiques accompagne un phénomène de gentrification commencé depuis les années 1980. Ce processus est caractérisé par de grands projets urbains, par le départ de groupes sociaux vulnérables et par des contestations et adaptations.

Comment la culture est-elle interprétée, détournée ou instrumentalisée par les acteurs concernés par ces projets? Dans ces "arènes ambiguës", des conflits patrimoniaux, des associations culturelles, des groupes et des individus bricolent et transforment des identités collectives et des traditions, en lien ou en réaction aux politiques publiques.

5 À Buenos Aires, ces politiques utilisent bien souvent le registre du multiculturalisme ou de la diversité culturelle pour mettre en avant la richesse des origines migrantes des habitants. Toutefois, comme l'affirment Maria Carman et Monica Lacarrieu, de tels discours sont souvent un prétexte pour exclure des populations défavorisées et stigmatisées et s'inscrivent dans un dispositif de gestion territorialisée des villes (Carman M., 2006 ; Lacarrieu M. et al., 2014). Dans les arènes culturelles étudiées, nous verrons l'existence d'exclusions dues notamment au choix d'un récit officiel. D'autre part, nous observerons que dans ces arènes les rôles ne sont pas figés, et que la 
patrimonialisation de la culture ou de l'art n'est pas une prérogative des seules politiques institutionnelles.

6 Seront ainsi présentés trois exemples d'arènes culturelles dans les quartiers de San Telmo, de La Boca et de Piedrabuena, où des projets sont vecteurs d'identités et de patrimonialisation et agissent contre la stigmatisation des médias et des institutions. Mes analyses sont en partie issues des matériaux récoltés lors de workshops franco$\operatorname{argentins}^{2}$ : de nombreux entretiens ont été réalisés, entre autres, à Barracas, San Telmo, La Boca en 2015 et 2016 (Morovich B., 2017). D'autres enquêtes et entretiens à La Boca et Piedrabuena ont été réalisés pendant les workshops de 2017, 2018 et 2019. La démarche suivie était celle de recherche-création ${ }^{3}$ qui mêlait l'approche anthropologique (observation des pratiques, entretiens), artistique (dessins, performances, vidéos) et urbanistique-architecturale (esquisses, suggestion d'un projet à présenter à des publics) dans le but de bousculer préjugés et représentations.

7 Ce travail de terrain montre, dans le cas de San Telmo, que plusieurs formes de résistance à la gentrification existent. La culture est convoquée à travers plusieurs registres. Celui des cultures urbaines est instrumentalisé en lien avec un projet de Centre culturel contre des habitants considérés illégaux. D'autre part, la culture comme identité à préserver est le prétexte pour des manifestations d'artistes et d'artisans contre la suppression d'une partie de la Feria (marché en plein air) dans le même quartier. En ce qui concerne La Boca, la création du Distrito de las Artes en 2013 s'adresse surtout à des acteurs externes au quartier qui favoriseraient un futur développement urbain local, afin d'accroître la valeur marchande du foncier. Là aussi, des mobilisations d'habitants, artistes et groupes socio-culturels dénoncent une culture de l'élite, invoquant une culture identitaire propre à La Boca et qui s'incarnerait dans des lieux historiques du quartier. Finalement, dans le quartier plus périphérique de Piedrabuena, le projet Galpon Piedrabuenarte montre comment l'action artistique de groupes sociaux défavorisés impulse des dynamiques culturelles identitaires et patrimoniales afin de changer l'image $\mathrm{du}$ quartier, dynamiques qui ne sont pas à l'abri de l'instrumentalisation par des politiques urbaines et culturelles en devenir. 


\section{Les Barrios al Sur : changement urbain et « districts » créatifs}

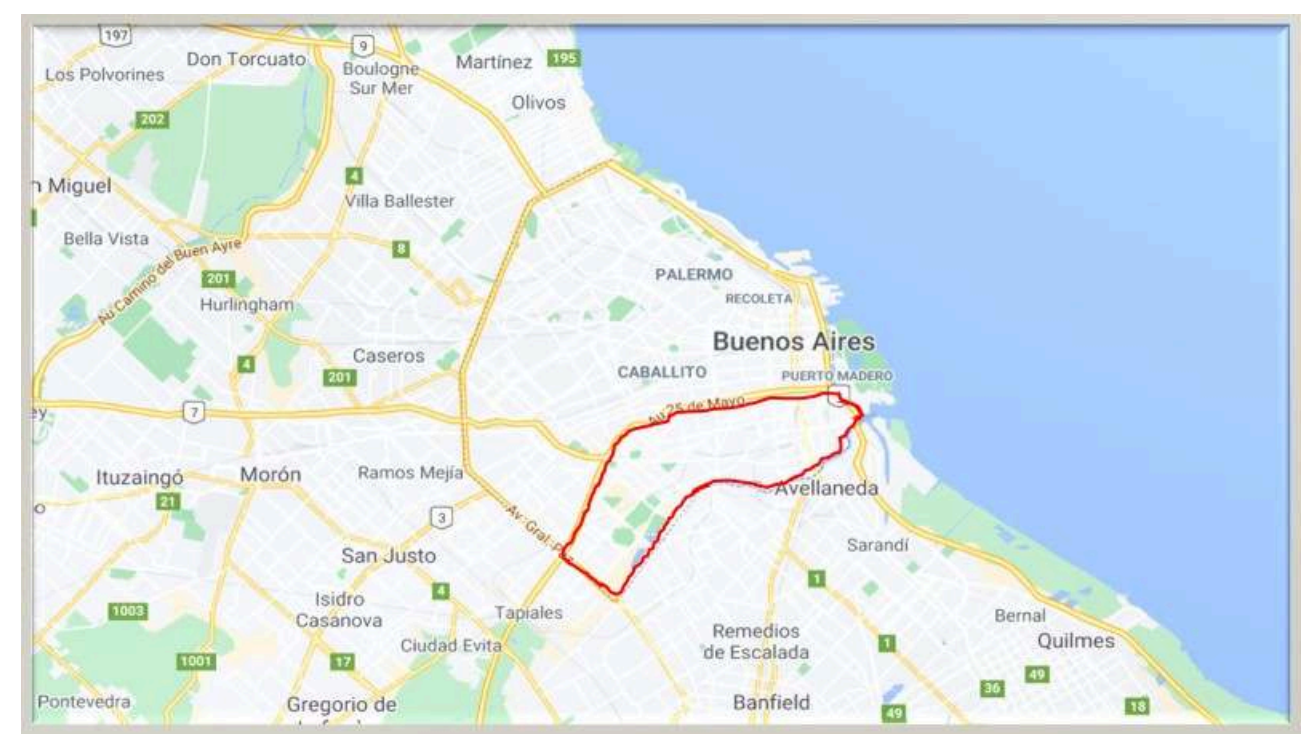

En rouge : Barrios al Sur, Ciudad Autónoma de Buenos Aires. A partir d'une carte Google Maps.

La ville ${ }^{4}$ de Buenos Aires est caractérisée par des déséquilibres territoriaux qui trouvent leur expression la plus marquée dans la division entre un nord résidentiel et privilégié et un sud industriel et défavorisé qui a commencé à être massivement revitalisé à partir des années 1990 selon un paradigme urbain néolibéral (Prévôt-Schapira M.F., 2001). La notion de "quartiers sud» peut sembler floue car elle implique des réalités urbaines sans doute diverses mais qui présentent de nombreux traits communs. Ce sont des quartiers industriels désaffectés ou caractérisés par l'habitat précaire (villas miserias), des quartiers populaires, des grands ensembles ou des anciens quartiers résidentiels paupérisés, tous relativement proches $\mathrm{du}$ cours d'eau Matanza-Riachuelo, particulièrement pollué. Ces contextes sont souvent stigmatisés et touchés par des processus de changement urbain, des patrimonialisations, des revitalisations. La présence de grands projets urbains de revitalisation comme celui de Puerto Madero indique ici l'intérêt de l'État pour les nouvelles politiques publiques (Herzer H., 2012). Ces projets sont à l'origine de phénomènes de gentrification qui émaillent le territoire de manière non uniforme et fragmentée, créant des fractures sociales et urbaines (Lacarrieu M., 1995).

En Amérique latine, les processus de gentrification ont été reliés à la conflictualité engendrée par l'urbanisme néolibéral qui, à partir surtout des années 1980, en parallèle avec des restructurations économiques, a souvent généré des formes de résistance (Delgadillo V., 2014 ; Hidalgo R. et M. Janoschka, 2014 ; López-Morales E., Bang Shin, H. et L. Lees, 2016; Rodríguez M.C., et M.M. Di Virgilio 2016). La gentrification est caractérisée par des déplacements de populations défavorisées et des discours étatiques agressifs de "reconquête urbaine" et de «revalorisation ». Selon María Carla Rodríguez et María Mercedes Di Virgilio, la relation entre les classes sociales, les espaces urbains et l'État sont le cadre au sein duquel se développe la gentrification à Buenos Aires (ibid., p. 4). 
Les Quartiers Sud ont été massivement touchés par ce phénomène à travers d'ambitieux projets urbains réalisés dans le cadre de partenariats publics-privés ${ }^{6}$. Le quartier historique de San Telmo commence à être préservé et patrimonialisé à partir des années 1980, mais c'est dans les années 1990 que nait le projet Puerto Madero. Ce dernier donne lieu à l'apparition d'un secteur cossu et symbolique de cette manière de faire la ville néolibérale, à travers une politique de "refonctionnalisation » d'aires centrales délaissées, la réhabilitation de hangars historiques et leur transformation en lofts luxueux (Prévôt-Shapira M.F., 2001).

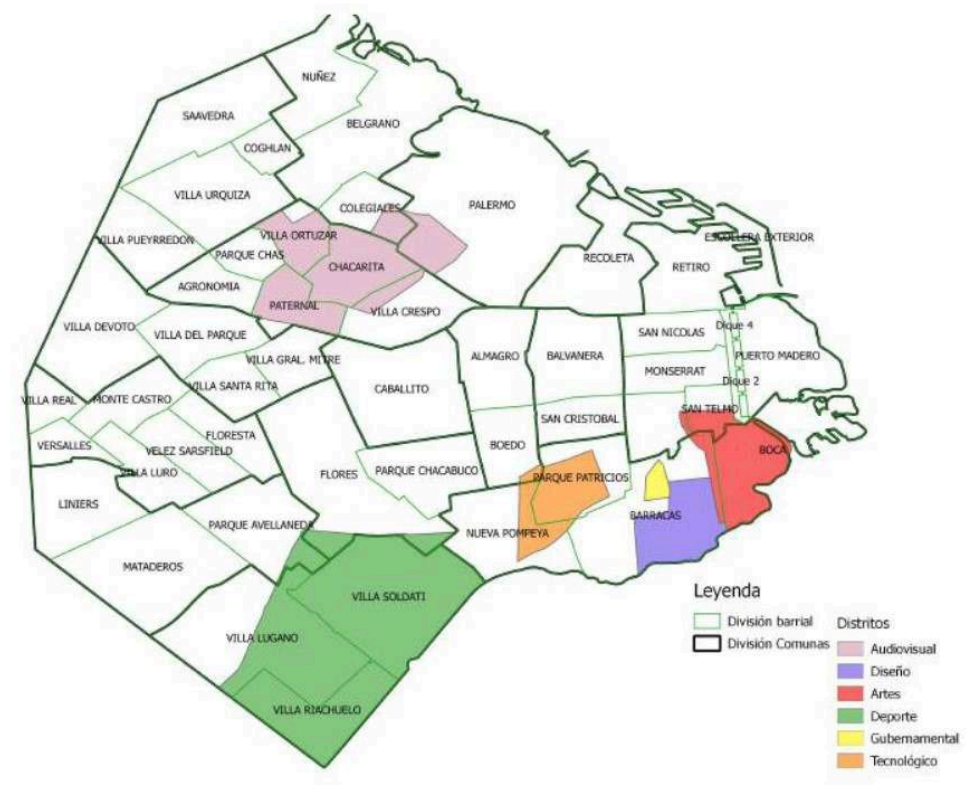

Districts créatifs de Buenos Aires. Source : Arqueros et González, 2017, p. 13

11 L'implantation de clusters, districts ou quartiers créatifs en cours dans plusieurs pays dans le monde, impulse des changements socio-économiques majeurs (Landry C. et F. Bianchini, 1995 ; Vivant E., 2009). À Buenos Aires, des pôles se développent à partir de 2008 dans les Quartiers Sud, initiés avec le Distrito Tecnológico dans le quartier Parque Patricios. Le Distrito Audiovisual est créé en 2011, le seul au nord du centre-ville, tandis que le Distrito de las Artes voit le jour en 2013 dans le quartier de La Boca. Le Distrito del Diseño est lui officialisé en 2014 à Barracas (Goicoechea M.E., 2018 ; A.G. Thomasz, 2016 et 2017). Les logiques pour la mise en place de ces clusters sont les mêmes. Il s'agit tout d'abord de favoriser des rénovations suite à l'implantation d'entreprises et de particuliers attirés par des avantages fiscaux. L'objectif est ensuite d'améliorer l'espace urbain à travers l'éclairage public et des espaces verts qui diminuent le caractère anxiogène du quartier (Goicochea M.E., 2018). Afin de garantir l'accessibilité, une politique de renforcement des transports publics est aussi mise en place. Finalement, la construction de bâtiments culturels iconiques, comme la nouvelle Casa de Gobierno par l'architecte Norman Foster en 2010 dans le quartier Parque Patricios, poursuit la gentrification des quartiers sud de la capitale argentine (Di Virgilio et Guevara 2014), symbolisant les changements en cours et attirant des usagers et des touristes. María Eugenia Goicochea (2018) indique que les mutations sociales induites par ces politiques ainsi que la hausse du prix du foncier sont particulièrement visibles dans le district 
technologique, à Parque Patricios, alors qu'elles seraient moins perceptibles à La Boca ou à Barracas. Toutefois, une dynamique irréversible est enclenchée.

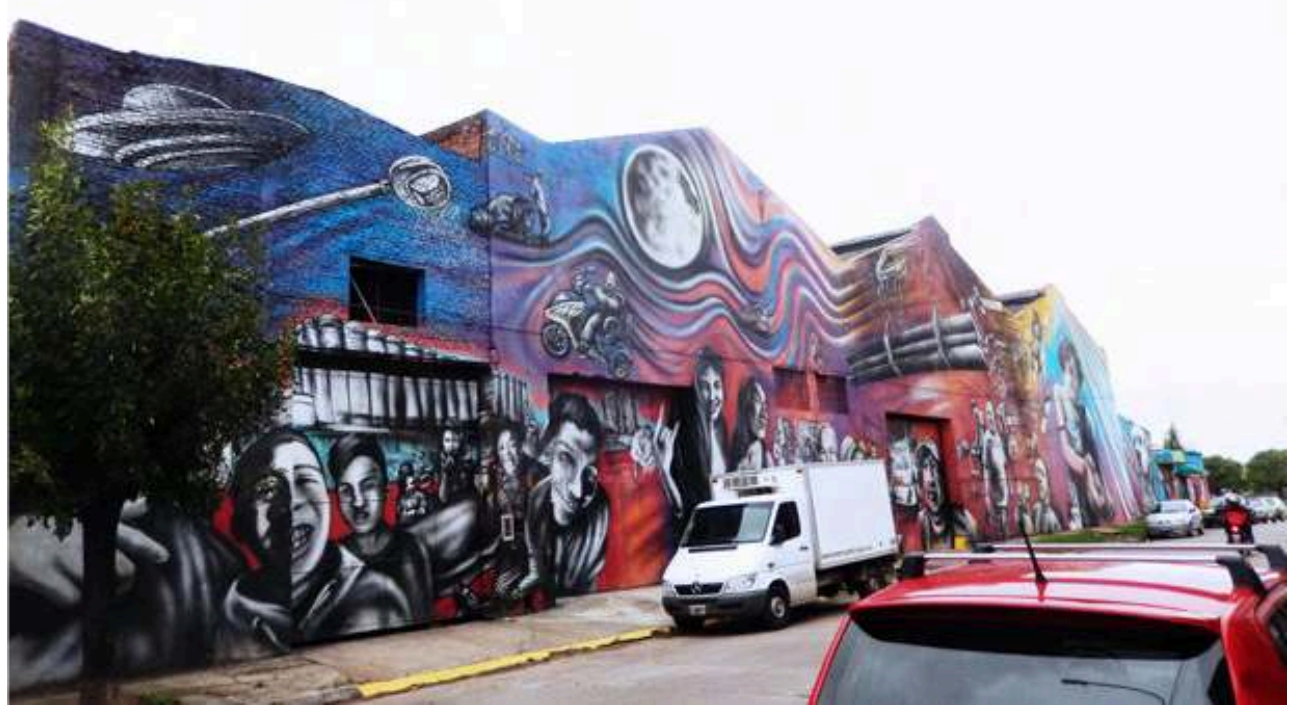

Présence de l'art à Barracas. Image de l'équipe des étudiants de Barracas, Workshop 2016.

Source : Barbara Morovich, 2017, p. 60

Lors des workshops franco-argentins, nous avons $\mathrm{pu}$ constater d'importantes transformations. Les projets de revitalisation de Barracas, la Boca et Parque Patricios cherchent désormais à faire cohabiter la mémoire des quartiers industriels avec des projets artistiques dans l'espace public. La présence de l'art est très significative et portée par des acteurs publics et des initiatives privées: à Barracas, par exemple, l'artiste Marino Santamaría est à l'origine d'un embellissement de la Calle Lanín (où il habite et travaille) à travers la décoration des façades des maisons (Santamaría M., 2015). Cette initiative individuelle, qui s'est diffusée aux maisons du voisinage, a favorisé la venue de touristes et a attiré l'intérêt de la ville pour une forme de patrimonialisation de la rue. Comme jadis à la Boca grâce aux initiatives de l'artiste Benito Quinquela Martín, l'art a participé à la transformation du quartier et contribue à la touristification.

13 Comme affirmé auparavant, la culture possède ici un caractère ambigu, plastique et somme-toute flou, qui loin des définitions figées, renvoie à des processus et à des négociations au sein desquels des acteurs se confrontent et parfois collaborent au sein d'arènes dont nous illustrerons quelques cas spécifiques. À Buenos Aires, la culture semble plus séparer qu'unir. Guénola Capron rappelle que l'opposition entre «civilisation» (incarnée par l'origine européenne) et «barbarie » (représentée par l'origine indigène et métisse) est au cœur de la construction identitaire de la ville, ce qui perdure encore actuellement (Capron G., 2001). Milena Annecchiarico montre, quant à elle, l'invisibilisation de la population noire argentine (2014:62), les Africains venus comme esclaves, puis leur descendance, étant absents dans la mémoire historique officielle de la nation; Maria Carman aborde la culture comme un " piège " tendu pour faire accepter de grands projets urbains, par exemple la reconversion du marché Abasto en centre commercial «culturel »: là aussi, il y a invisibilisation des secteurs populaires comme si ces couches sociales pourtant historiques dans le quartier n'étaient pas productrices de culture (Carman M., 2006: 256). À travers le cas du 
bâtiment Pa.De.La.I (Patronato de la Infancia), je montrerai qu'une telle invisibilisation concerne aussi des populations de migration plus récente dans le quartier de San Telmo, non reconnues comme porteuses de culture et volontairement écartées.

Monica Lacarrieu signale que la "revalorisation" ne concerne pas seulement des centres historiques où des édifices patrimoniaux sont présents, mais également des quartiers plus périphériques, où il est possible de « réactiver des sites, des pratiques et des activités culturelles, en mettant en scène des structures symboliques associées à divers biens $»^{7}$ (Lacarrieu M., $2016: 31$ ). C'est le cas des exemples analysés ici.

\section{La « culture » comme vecteur de patrimonialisation incertaine à San Telmo}

15 Dans son mot introductif au livre sur le "Centre historique » (Plan de Manejo del Casco Histórico, 2015 :12), le Ministre de la Culture argentin insiste sur l'importance de l'amélioration de l'environnement et le développement des activités culturelles et touristiques de la zone de San Telmo et Monserrat, anciens quartiers d'installation de la bourgeoisie portègne ${ }^{8}$. Cette zone serait caractérisée par un «mélange social et culturel important ", au-delà des richesses architecturales et historiques. San Telmo est le lieu mythique de la fondation de Buenos Aires aux XVII ${ }^{\mathrm{e}}$ et XVIII ${ }^{\mathrm{e}}$ siècles. Paupérisé à partir de l'épidémie de fièvre jaune de 1875 , ce quartier reste aujourd'hui hétérogène et mixte, connu pour ses ambiances bohèmes et pour être un des hauts lieux du tango argentin, surtout dans des formes patrimonialisées et touristicisées. Le tourisme est un élément fondamental de la revalorisation urbaine de San Telmo où le tango ${ }^{9}$ attire des visiteurs par un marketing urbain très particulier fait de culture musicale, de danse mais aussi d'héritage architectural (Gómez Schettini A. et D. Zunino Singh, 2008; Gómez Schettini M., Almirón A. et M. González Bracco, 2011). Des actions comme la valorisation des Bares Notables ou des politiques de sensibilisation au patrimoine concernent aussi ce quartier.

Les transformations urbaines se prêtent ici également à des controverses en raison des critères choisis pour patrimonialiser (ou pas) un lieu, un édifice, une manifestation. À San Telmo, la «culture » se décline au pluriel, car au-delà de la patrimonialisation immatérielle du tango, les quartiers sud sont, au moins en partie, habités par des populations migrantes: quelle place offrir à leur «culture»? Quelles sont les négociations possibles?

17 Depuis les années 1980, des réhabilitations privées sont menées par les classes moyennes et en 1991, le quarter devient Área de préservación histórica (APH1). En 2001, la sauvegarde du quartier revient au Ministère du Planeamiento (Planification) à la Culture. Quelques îlots font l'objet de réhabilitation, l'éclairage et un circuit piéton touristique sont aussi mis en place. Mais une véritable politique d'amélioration de l'habitat plus défavorisé n'est pas prévue (Diaz Orueta et al., 2003 : 171-172). Ce quartier représente donc un cas paradigmatique de la gentrification imparfaite, typique des Quartiers Sud: une gentrification fragmentée par îlots urbains qui fait qu'une forme de mixité peut coexister. La gentrification est contrée notamment par des associations locales, comme le Movimiento de Ocupantes e Inquilinos (MOI) qui lutte pour un habitat digne, obtient la régularisation d'immeubles suite à des revendications et est très actif dans la dénonciation des expulsions ${ }^{10}$. Le MOI est le résultat de la rencontre entre des étudiants 
et des enseignants de l'Université de Buenos Aires, des mouvements populaires pour l'occupation massive de logements et du mouvement des prêtres ouvriers dans les années 1980. L'officialisation de cette structure en 1991 est liée à un cas emblématique : l'occupation d'un complexe architectural patrimonial, l'ex-Padelai et la résistance à l'expulsion, puis son autogestion par une centaine de familles d'origine migrante sans logement (Jeifetz N. et M.C. Rodríguez, 2006).

Le bâtiment du Patronato de la Infancia, appelé Pa.De.La.I (structure philanthropique pour enfants en difficulté) est abandonné dans les années 1970 et donné à la Ville de Buenos Aires. L'occupation par des familles précaires commence en 1984 et donne naissance quelques années plus tard à une Coopérative (Cooperativa de Vivienda, Crédito y Consumo San Telmo) qui cherche à négocier la propriété de l'édifice. Malgré une ordonnance municipale qui régularise la propriété en 1991 et un accord entre la Coopérative, la Municipalité et l'Université de Buenos Aires pour la construction d'un projet d'habitat social en 1992 (ibid.), les familles sont finalement délogées en 2003 et l'édifice destiné à la démolition. Suite à des contestations fondées sur la valeur patrimoniale de l'ensemble architectural ${ }^{11}$, la démolition est suspendue et, en 2009, le bâtiment est confié pour 30 ans à la Agencia Española de Cooperación Internacional para el Desarrollo, pour être transformé en Centre Culturel Espagnol ${ }^{12}$. L'exposition Sinvergüenza! Intervenciones Urbanas Iberoamericanas en 2010, montre un usage de l'art urbain significatif pour un lieu qui est dans une phase de mutation: durant deux semaines, les murs internes de l'ex-Padelai sont peints par des artistes graffeurs qui utilisent le registre de l'art engagé et attirent un nombreux public (Golte M., 2011 : 43-53) mais sans aucune mention des populations délogées. La transition entre le souvenir d'un édifice occupé par des populations défavorisées et stigmatisées vers un centre culturel et artistique se fait par des images contestataires qui sont mises au service du commanditaire, c'est-à-dire d'un art urbain institutionnalisé et consensuel (Le Gallou A., 2018). 


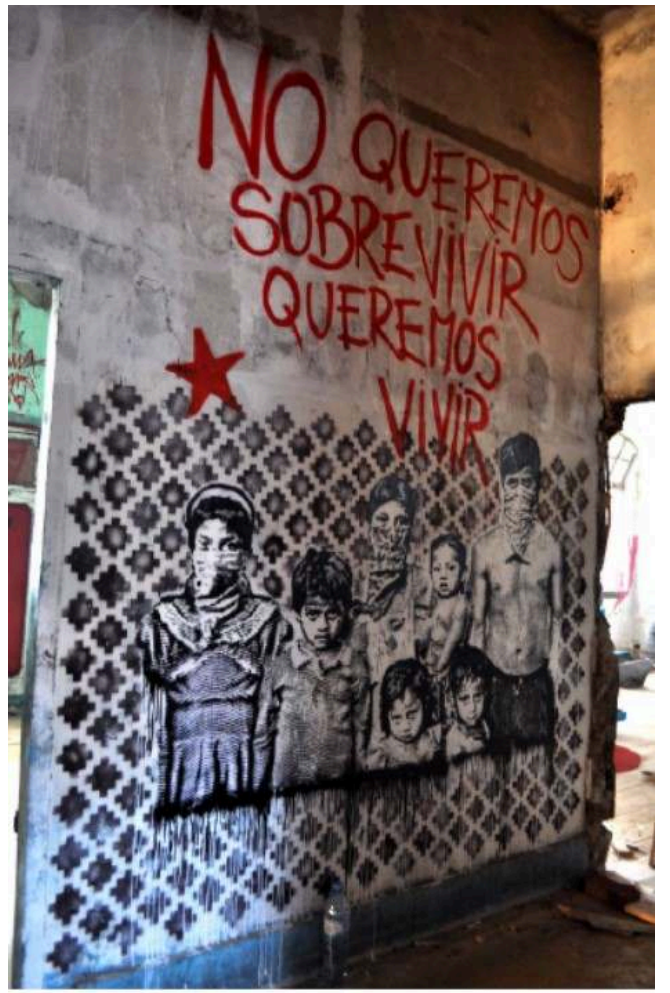

Fuvre de Nazza Stencil, Exposition Sinvergüenza ! Source : Golte M., 2011 : 48

19 C'est un «rite de passage » porté par l'art et les artistes, et vérifié dans d'autres contextes (Morovich B., 2014). Dans le cas de l'ex-Padelai, l'art défie parfois les commanditaires : c'est le cas de Nazza Stencil, artiste argentin engagé, dont l'une des œuvres est censurée avant l'ouverture de l'exposition car elle montrait un membre de la royauté espagnole décapité (Golte M., 2011: 52). Néanmoins, ces graffitis et ces œuvres ne sont pas en lien avec les mémoires des anciens occupants. Finalement, le Centre Culturel d'Espagne, faute de moyens, quitte le lieu sans effectuer de rénovation. En 2012, l'occupation reprend. Les mêmes habitants reviennent et réclament le droit à l'habitat jadis promis par la Municipalité. Ils ne sont pas opposés à une transformation de la structure en centre d'art ouvert à tous et sont prêts à négocier leur droit de propriété contre un logement digne. Cette deuxième occupation du " Patro ", c'est ainsi qu'ils appellent l'édifice, dure jusqu'en 2017. Après une lutte de 30 ans, la Coopérative considère que le conflit avec la municipalité sur le projet d'un logement social dans le Centre historique, là où sévit la spéculation immobilière, est un symbole fort. 


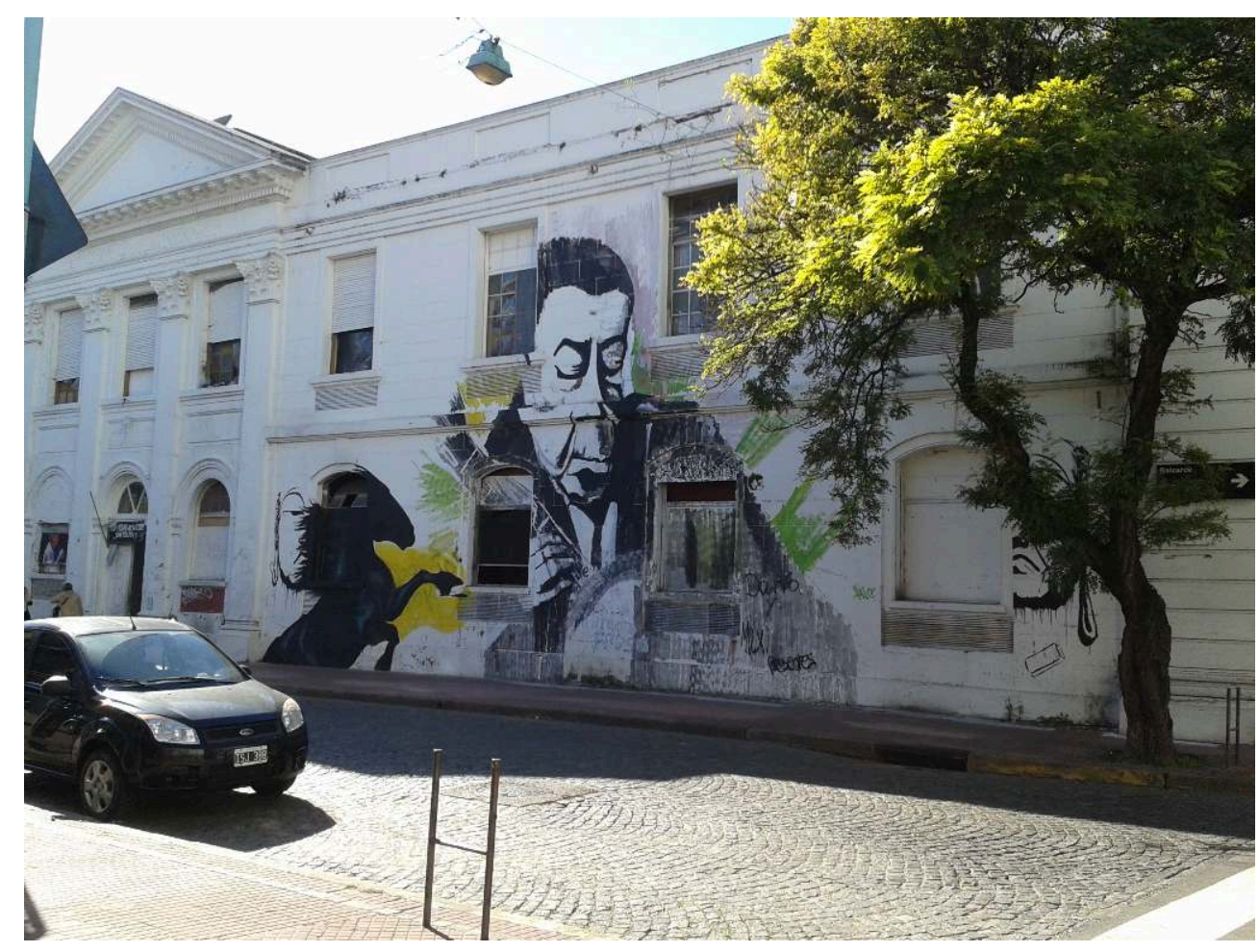

Barbara Morovich

Mais un délogement définitif intervient en $2017^{13}$. Les familles reçoivent des aides, mais pas les logements espérés. L'édifice destiné à un usage public sera définitivement converti en siège de la Comuna 1 du gouvernement de la ville de Buenos Aires l'année suivante $^{14}$. Il n'est pas étonnant que la rénovation porte sur la revalorisation de la façade d'origine dont la restructuration est portée par la Comisión para la Preservación del Patrimonio Histórico de la Ciudad. Le projet de transformer le complexe en siège du Ministère de la Culture est finalement abandonné ${ }^{15}$, toutefois la culture reste présente avec l'idée d'une place ouverte à des actions en ce domaine ${ }^{16}$. Dans cet exemple, le registre consensuel de l'art et de la culture est utilisé pour déloger des familles défavorisées.

21 Une autre forme de résistance à la gentrification à San Telmo concerne, elle, des artistes et des artisans, engagés dans un conflit entre deux associations, les Artesanos unidos de la calle Defensa et El Adoquín. Cette dernière signe en 2019 un accord avec la Municipalité pour légaliser la Feria artesanal, en échange de l'abandon d'une partie de la Calle Defensa par les manteros ${ }^{17}$. La Calle Defensa, artère centrale du quartier, est caractérisée par la présence de nombreux antiquaires, mais aussi par un évènement hebdomadaire majeur, la Feria, marché d'artisanat en plein air qui attire une foule de touristes chaque samedi. Selon l'accord signé avec la Municipalité, une partie de la Calle serait désormais laissée libre, en accord avec les magasins d'antiquaires mais surtout en raison de futurs projets urbains ${ }^{18}$. Les occupants de la zone concernée, membres de l'association El Adoquín, sont déplacés dans une autre partie de la Calle, aux dépens d'autres artisans et artistes. Ces derniers se sentent trahis et forment une autre association (Artesanos unidos de la calle Defensa). Ce processus réactive l'antagonisme entre les vendeurs d'antiquités (les établis), installés à San Telmo depuis les années 1960 , et les manteros (ambulants non-établis) qui sont arrivés suite à la crise économique de 2001-2002 occupant toute la rue (Lacarrieu M., 2016: 35-36). Cette 
dynamique avait été observée et relatée lors du workshop franco-argentin de 2015 qui avait recueilli les témoignages de certains commerçants de deux groupes, puis observée de nouveau lors de balades urbaines en 2019. Malgré ces tensions, plusieurs tentatives d'éviction de la part de la municipalité n'avaient pas abouti par le passé, à cause de la résistance des artisans et artistes, en lien avec certains habitants et malgré l'opposition des vendeurs d'antiquités (ibid.).

Les artisans de l'association Artesanos unidos de la calle Defensa, délogés manu militari plusieurs fois par la police mais toujours présents, expliquent en février 2019 leur mobilisation :

Pour l'identité et la culture, contre la répression et le délogement, nous défendons le marché que nous avons construit pendant une décennie. Un marché qui fait de l'espace public un lieu historique d'intérêt communautaire capable de refléter la richesse sociale de notre peuple.

Site Facebook « Artesanxs unidxs de la calle Defensa »

Nous sommes face à un autre processus de patrimonialisation incertaine, avec ses soubresauts et la complexité de ses disputes, de ses alliances et de ses revirements : pour contrer l'éviction, les artisans délogés s'approprient la sémantique de la culture comme «identité » du quartier et parlent de la construction " historique » de la Feria comme espace public d'intérêt commun, capable de « refléter la richesse sociale » du peuple en opposition à la culture élitiste des antiquaires qui se rangent du côté des rénovateurs et de la gentrification.

La sauvegarde de cet espace et de ses acteurs s'incarne ici en l'invention d'une tradition (Hobsbawm E. et Ranger T., 2006) : la feria n'est pas une institution très ancienne, mais reflète l'esprit d'un quartier et d'un groupe patrimonial qui a su jusque-là composer avec la gentrification. Elle s'est construite dans la lutte et demande le droit à la ville.

\section{La Boca « Distrito de las artes » : fragmentation urbaine et muséification}

Quartier de 330 hectares, dégradé et à fort risque d'inondation, La Boca était le port d'arrivée des migrants à Buenos Aires. Ce quartier ouvrier s'est urbanisé à partir du XIX siècle. Après l'abandon de l'activité portuaire, il se vide de sa population et les habitations se détériorent. Le quartier est marqué par de fortes structures sociales et communautaires, des cantines (comedores), des structures artistiques et associatives, et également par la présence d'artistes indépendants qui exposent dans la rue.

Lors des workshops de 2016 et 2017, différents acteurs adhérents à ces structures ont été interviewés. Ils attestent d'une stigmatisation du quartier, compensée par la solidarité et l'investissement bénévole des habitants. Le plus connu des artistes de La Boca, Benito Quinquela Martín (1890-1977), fut à l'origine d'un véritable changement urbain du quartier, par la création de plusieurs institutions: Escuela Museo Pedro de Mendoza, Instituto Odontológico Infantil, Teatro de la Ribera, etc. De plus, dans les années 1950, ses peintures colorées des façades des maisons populaires ont modifié le Pasaje Caminito, attraction touristique majeure de La Boca. Ces maisons colorées, une « invention culturelle », deviennent l'emblème du quartier comme s'il s'agissait d'une tradition historique. Et c'est notamment autour de ces maisons que s'organise une partie de la requalification du quartier (Lacarrieu M., $2016: 32$ ). À partir des années 1980, la récupération des conventillos (habitat populaire construit probablement par des 
immigrants italiens venant de Gênes à la fin du XIX $x^{e}$ siècle), se fait à travers le programme RECUP-Boca, de 1984 à 1986, qui vise à consolider le maintien des habitants défavorisés dans le quartier. La reconquista urbana impulsée par RECUP-Boca implique des dynamiques participatives, certes parfois instrumentales, mais qui mettent en avant le sentiment d'appartenance au quartier, sa culture, son identité (Programa Recup Boca: Una carta de desarrollo social y urbano del barrio, p. 7, cité par Thomasz A.G., 2017). Pourtant, ce programme n'a pas mis fin à la paupérisation ni entravé la gentrification du quartier.

La création du district artistique (Distrito de las Artes) en 2013, qui prévoit la réhabilitation d'édifices à destination artistique, n'implique pas les habitants mais plutôt des acteurs externes au quartier, qui seraient moteur d'un développement urbain local futur. Les artistes rencontrés lors des workshops de 2016 et 2017 font état de la richesse des projets et des activités artistiques, qu'ils soient internes ou d'origine externe au quartier. Dans le premier cas, on trouve Guillermo Alio, né à la Boca et ayant voyagé à travers le monde pour des performances artistiques en lien avec le tango, puis revenu à Buenos Aires. Désormais, il réside et travaille dans son quartier d'origine où il peint son environnement. Installé sur le Caminito, il y expose ses tableaux colorés pour les touristes. Dans le deuxième cas, Pablo Caracuel et Sonia Neuburger, sont parmi les artistes de la Oficina Proyectista ayant impulsé les Expediciones a Puerto Piojo, une ancienne plage de la Boca présente dans les souvenirs des habitants. Cette proposition artistique, présentée à la Fundación Proa en 2014, met en avant l'importance du Riachuelo comme lieu d'activités populaires. Lors de l'entretien, les deux artistes ont affirmé qu'ils cherchaient ainsi à donner de la visibilité au fleuve comme paysage urbain «pour toute la ville de Buenos Aires».

Malgré des projets qui se veulent connectés à la vie sociale du quartier, la création du Distrito de las Artes ne permet pas une circulation et un mélange des publics et s'adresse surtout à des initiés de l'art contemporain. De plus, sa localisation participe à la hausse de la valeur marchande du foncier dans ce secteur, ce qui provoque le départ des plus défavorisés : selon Ana Gretel Thomasz (2017), en 2016 plus de 1000 habitants du quartier ont été délogés.

À La Boca, le sens à donner à la culture, au patrimoine et à l'identité provoque alors des débats entre des organisations en compétition. Les processus de patrimonialisation sont loin d'être univoques : quel passé culturel conserver, quel art mettre en avant ? Faut-il conserver ou plutôt s'adapter à des contraintes économiques contemporaines qui répondent à des logiques globalisées ? Diaz-Orueta et al. (2003 : 182) évoquent ainsi une compétition entre les preservacionistas et les progresistas. Les enquêtes de terrain d'Ana Gretel Thomasz montrent des mobilisations et des réunions d'habitants, artistes et groupes socio-culturels travaillant dans le quartier qui dénoncent la culture "pour une élite ", celle qui fait vendre, la distinguant de la culture " propre au barrio » et à son identité, en lien avec le droit au logement et à la sauvegarde du patrimoine local. Les personnes qui s'expriment dans les réunions soulignent notamment que le Caminito est en quelque sorte un « antécédent » du Distrito de las Artes et que le projet de l'État s'est inspiré de la réputation artistique de la Boca en l'instrumentalisant. Pourtant euxmêmes, comme les artistes peintres installés dans le Caminito, ont profité du quartier.

Plusieurs structures récentes en relation avec l'art représentent à la Boca le signe du changement urbain, comme la Usina de las Artes qui a vu la transformation d'une 
ancienne usine d'électricité en espace culturel inauguré en 2012 ou encore la Fundación Proa, consacrée à l'art contemporain.

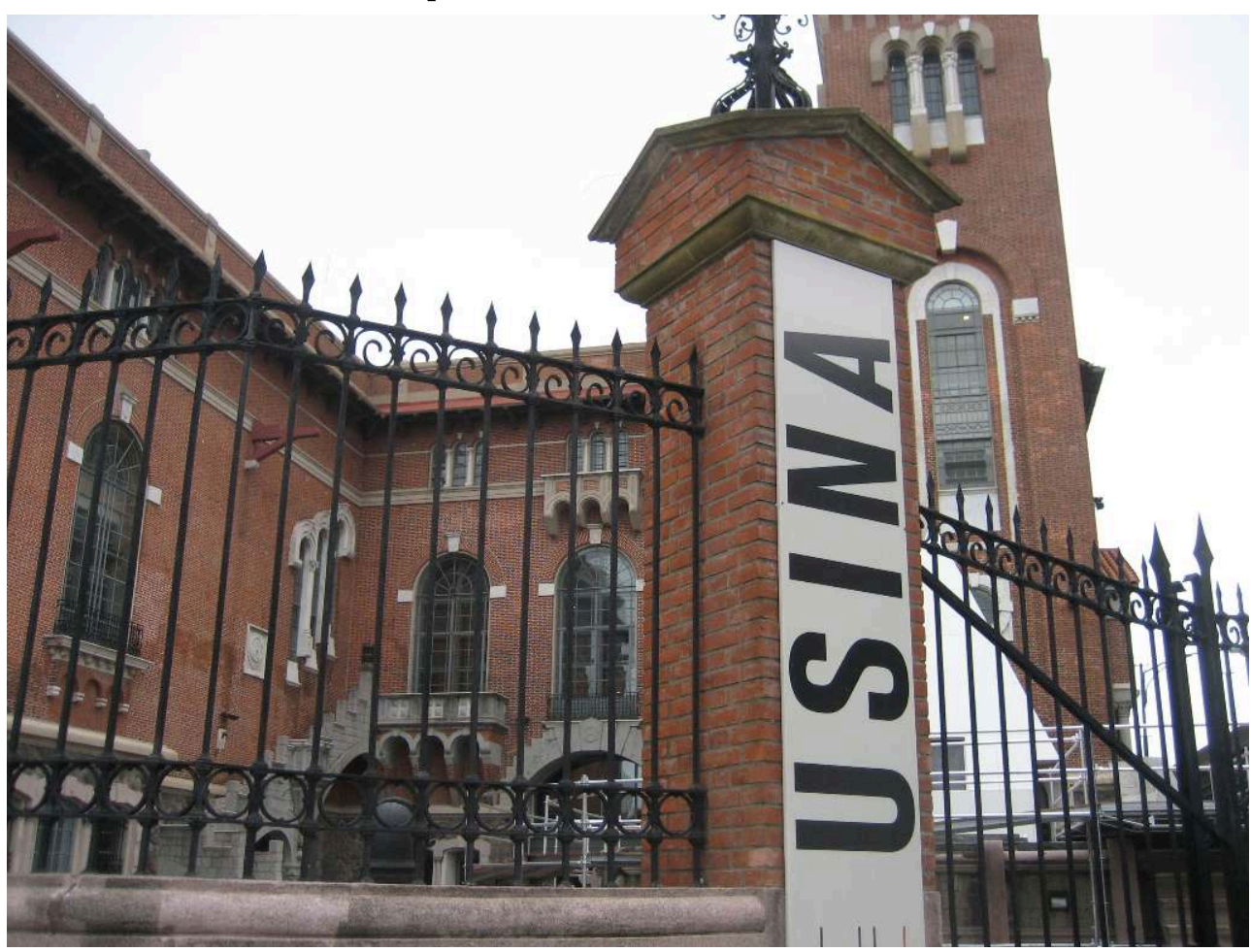

La Usina del Arte

Barbara Morovich

31 Ces structures, par leur forme urbaine et leurs clôtures, ne sont pas tournées vers le quartier et ses habitants, mais essayent d'attirer des nouveaux publics, notamment des touristes. Ici, comme à San Telmo, les circuits touristiques sont mis en place pour éviter certaines rues, considérées comme dangereuses, et aiguillent les visiteurs vers le Caminito et les bâtiments cités qui sont aussi des «objets signes » du changement urbain en cours.

\section{Piedrabuena : un Galpon artistique contre la stigmatisation}

La patrimonialisation des quartiers défavorisés est un fait avéré en Amérique latine. Le cas emblématique des favelas montre comment la patrimonialisation $\mathrm{du}$ paysage culturel de Rio a accompagné sa mise en tourisme et son esthétisation, et parallèlement a été la cause de tensions générées par l'application d'un modèle patrimonial exogène à un contexte défavorisé (Berenstein Jacques P., 2003 : 32-39 ; Zamant V., 2017 : 94-120). Ici il s'agit bien d'analyser une initiative dans un contexte défavorisé, le quartier Piedrabuena, sauf que le processus de patrimonialisation n'est pas ici impulsé par des institutions nationales ou internationales mais à l'initiative d'un groupe d'habitants. Dans ce sens, le Galpón Piedrabuenarte montre comment l'action des groupes sociaux défavorisés impulse des dynamiques patrimoniales qui restent, ici également, incertaines, et peuvent être ensuite appropriées par des institutions. Il montre surtout une volonté forte de changer l'image négative d'un quartier comme dans de nombreux 
cas de quartiers stigmatisés, à travers des actions artistiques et culturelles en lien avec des partenaires extérieurs et intérieurs (Morovich B., 2017 2). À contre-pied des théories qui associent de manière déterministe les artistes à la gentrification (Ley D., 2003), ces initiatives semblent profiter avant tout à des habitants, mais courent le risque d'être instrumentalisées par des politiques urbaines.

Piedrabuena est un grand ensemble (conjunto habitacional) du quartier Villa Lugano, qui concentre le plus d'habitat précaire de toute la ville de Buenos Aires. Construit entre les années 1950 et 1980 selon un style moderniste, Piedrabuena est un quartier stigmatisé avec des problèmes infrastructurels. Il est habité par des populations défavorisées, notamment des familles délogées de la Ciudad Oculta, un quartier auto-construit précaire, également dans les Quartiers Sud.

Piedrabuena a progressivement fait de la place à l'art et à la culture par son architecture impressionnante. Tout d'abord le quartier a été le lieu d'actions initiées par des artistes extérieurs pour des clips, des publicités et même des séries télévisées. Le cadre saisissant de ses structures urbaines, les lieux évoquant une scénographie à ciel ouvert ont alors nourri des approches esthétiques.

Le travail photographique de l'artiste suisse Gian Paolo Minelli, des "autoportraits concertés" avec des vues de l'environnement urbain quotidien des adolescents interviewés, est un projet qui a pris une importance considérable dans le quartier. Dans un entretien ${ }^{19}$, l'artiste affirme que son intégration au quartier s'est faite progressivement, quand les habitants ont compris que les photos pouvaient être aussi une forme de lutte sociale et l'occasion de dénoncer leurs problèmes. Ici l'art semble avoir une valeur d'inclusion et ne correspond pas à une injonction venant des institutions, mais à un moyen de révéler la précarité et en même temps à la volonté de sortir certains habitants de la précarité.

L'un d'entre eux a été mis en avant par un documentaire du même artiste suisse: "Buenos Aires, Zona Sur : Luciano y el arte de vivir en Piedrabuena». Il retrace l'histoire du projet Piedrabuenarte à travers le portrait d'un initiateur du projet, l'artiste Luciano Garramuño. Peut-être inspirés par d'autres artistes venant de l'extérieur et voyant comme l'art pouvait être mobilisateur de rencontres, Luciano, Juan Garachico et Roy Falco les trois habitants de Piedrabuena, occupent en 2006 un hangar laissé par le théâtre Colon qui contenait encore des sculptures en plâtre et des scénographies. Selon Luciano, le Galpón Piedrabuenarte a été à l'origine d'une « révolution socioculturelle dans le quartier $"$.

Les projets du Galpón sont aujourd'hui très nombreux car Luciano et les autres membres du collectif ont pu tisser des liens avec de grandes structures culturelles, des facultés d'architecture ou d'art, des artistes, la municipalité et de nombreuses associations. Le Galpón est désormais un « lieu d'intérêt culturel de la nation » comme Luciano nous le dit lors d'un entretien en 2018 et comme nous le confirment les sites consultés. Il est désormais au centre d'une dynamique autour de l'art et de l'inclusion sociale, symbole d'une résistance à la stigmatisation par l'activité artistique, bien qu'il ne bénéficie pas de beaucoup de fonds. Le lien avec les habitants est crucial, des nombreux ateliers pour les enfants, des événements dans l'espace public, des vidéos qui dénoncent les mauvaises conditions d'habitation en font état. Les artistes du Galpón se mettent aussi en relation avec l'extérieur. Luciano s'est fait tatouer le quartier sur son corps: "Je porte les tours... sur ma peau comme reconnaissance... je porte tout le quartier comme démonstration d'un sentiment que je ne peux pas expliquer avec des mots». La 
patrimonialisation du quartier Piedrabuena, activée par le projet Piedrabuenarte, passe non seulement par des images des espaces du quartier en lien avec le Galpón et démultipliées sur les réseaux sociaux, mais aussi par le corps de l'artiste comme support des images patrimoniales. Toutefois, par le manque de fond réguliers et malgré les efforts des porteurs du projet, cette forme de patrimonialisation reste incertaine.

Luciano est également présent dans des vidéos tournées par le Ministère du Logement dans lesquelles il est question de rénovation du quartier. On est loin ici d'une forme de gentrification par la culture, mais peut-être cède-t-on à des formes d'instrumentalisation politique. Cependant il est clair que la force de ce collectif est d'être issu du quartier et de bien comprendre les enjeux d'habitants défavorisés dont Luciano se fait le porte-parole.

Avec mes collègues argentins et des étudiants, français et argentins, nous avons rencontré Luciano pendant le workshop franco-argentin de 2018. Il nous a accueillis dans un lieu particulier, un lieu de réunion qui avait été construit par des étudiants de l'Université d'architecture de Morón pour leur diplôme, le "Dome». Nous nous sommes alors trouvés dans une situation de don-contre don entre le collectif du Galpón et les "extérieurs" (étudiants et enseignants) : l'accès aux interlocuteurs, les entretiens et la matinée d'étude avaient été négociés en souvenir de la construction du Dome. Dans ces moments de rencontre, nous restions des acteurs très différents par notre origine sociale mais nous avions le but commun de participer à des formes de destigmatisation du quartier, notamment à travers l'expression culturelle. C'est ce que j'appelle une " arène culturelle » : nous négocions notre place en tant qu'individus ou en tant que groupe, par rapport à des enjeux qui, bien que différents n'en étaient pas moins, en partie, compatibles.

\section{Conclusion}

La «culture » est aujourd'hui souvent mise en avant et parfois prise en otage comme prétexte, justification ou publicisation des politiques et des changements urbains majeurs à travers le répertoire consensuel de l'art qui plait à tout le monde. Cet article a analysé des "arènes culturelles » au sein desquelles des usages polyvalents de la «culture » sont explorés, grâce à l'exemple des Quartiers Sud de la capitale argentine. L'implantation de clusters ou districts créatifs ou économiques, accompagne un phénomène de gentrification de ces quartiers. Ce travail d'enquête montre la vivacité de ces arènes, la patience de leurs acteurs, leur résistance, leur capacité à freiner le processus de gentrification à travers des contestations à très long terme, parfois des adaptations. Il montre aussi que l'ambiguïté du concept de culture et ses usages admet des appropriations en fonction d'enjeux différents, parfois divergents.

41 Bien qu'à des degrés différents, certaines similitudes peuvent être signalées. Tout d'abord le caractère incertain des patrimonialisations évoquées, car ces formes de patrimonialisation sont portées par des groupes à faible pouvoir économique. Toutefois, dans ces processus, ces acteurs culturels ne renoncent pas à leurs luttes qui s'insèrent dans le long terme de la revitalisation d'un quartier et de son changement d'image. Mais quelle place détiennent les artistes dans ces processus? Nous avons vu que l'ambiguïté de leur position et l'instabilité des arènes culturelles qu'ils intègrent démontrent que bien souvent ils n'agissent pas en gentrifieurs, mais qu'ils sont plutôt instrumentalisés par des dynamiques en cours qui les dépassent (Vivant E. et Charmes 
E., 2008). Dans d'autres cas, ils participent à des luttes pour renforcer l'identité d'un quartier ou d'un secteur d'un quartier en compétition avec d'autres groupes plus favorisés et en lien avec des populations défavorisées. Il arrive aussi qu'ils se mettent en réseaux avec de nombreux acteurs en dehors de leur quartier et qu'ils cherchent des alliances à long terme.

Le concept d'arène culturelle permet de percevoir ces dialogues, ces enjeux partiellement communs, ces accords et ces désaccords qui montrent que la culture est une construction constante entre des politiques publiques qui cachent des enjeux urbains et des acteurs qui cherchent à consolider une identité culturelle locale en défense de leurs acquis. Comme ce travail l'a démontré dans le cas du Pa.de Lai., la culture a également ses exclus.

\section{BIBLIOGRAPHIE}

Annecchiarico, Milena, « Afrologías porteñas y habaneras. Conexiones, contrastes y algunas reflexiones ", in Alejandro Grimson (coord.) Clacso, Culturas politicas y politicas culturales, Buenos Aires, 2014, p. 57-74.

Arqueros, Soledad et González, Carolina, « La política de distritos del sur de Buenos Aires: una mirada en perspectiva ", Quid 16: Revista del Área de Estudios Urbanos, n 7, 2017, p.7-29.

Artesanxs unidxs de la calle Defensa, Site Facebook, https://www.facebook.com/ artesanxsresistiendo/, page consultée le 12 septembre 2020.

Berenstein Jacques, Paola, « Patrimônio cultural urbano : espetaculo contemporâneo ? ", Revista de Urbanismo e Arquitetura, vol. 6, n 1, 2003, p. 32-39.

Bustamante, Mauricio, «Les politiques culturelles dans le monde. Comparaisons et circulations de modèles nationaux d'action culturelle dans les années 1980 », Actes de la recherche en sciences sociales, $\mathrm{n}^{\circ} 206-207,2015$, p. 156-173.

Capron, Guénola, « Buenos Aires ou le rêve inachevé », Espaces et sociétés, n 104, 2001, p. 109-126.

Carman, María, Las trampas de la cultura. Los "intrusos" y los nuevos usos del barrio de Gardel, Buenos Aires. Paidós, 2006.

Clarín, « Vuelven ocupar Padelai, piden viviendas », Clarín, 10 Mai 2012, https://www.clarin.com/ ciudades/vuelven-ocupar-padelai-piden-viviendas_0_r1gweHNnw7g.html, page consultée le 12 septembre 2020 .

Delgadillo, Victor, « Ciudad de México: megaproyectos urbanos, negocios privados y resistencia social », in Rodrigo Hidalgo et Michael Janoschka (eds.), La ciudad neoliberal : gentrificación y exclusión en Santiago de Chile, Buenos Aires, Ciudad de Mexico y Madrid, Santiago, Universidad Católica, 2014, p. 179-198.

Díaz Orueta, Fernando, Lourés María Luisa, Rodríguez, Carla, Devalle, Verónica, « Ciudad, territorio y exclusión social. Las políticas de recualificación urbana en la ciudad de Buenos Aires », Reis, n¹03/03, 2003 p. 159-185. 
Di Virgilio, Mercedes et Guevara, Tomás, « Gentrificación liderada por el Estado y empresarialismo urbano en la Ciudad Autónoma de Buenos Aires », Revista Estudios Sociales Contemporáneos, $\mathrm{n}^{\circ} 11,2014$, p. 12-23.

Djament-Tran, Géraldine, et San Marco, Philippe, La métropolisation de la culture et du patrimoine, Paris, Éditions Le Manuscrit, 2014.

Domínguez, Norma, « Gian Paolo Minelli y el arte de lo imposible », swissinfo.ch, 21 Octobre 2008, https://www.swissinfo.ch/spa/gian-paolo-minelli-y-el-arte-de-lo-imposible/6983784, page consultée le 13 septembre 2020.

El Grito del Sur, « Una reconversión con historia », El Grito del Sur, 5 Aout 2018, https:// elgritodelsur.com.ar/2018/08/una-reconversion-historia-padelai.html, page consultée le 11 septembre 2020 .

Expediciones a Puerto Piojo, « Expediciones... en PROA », Expediciones a Puerto Piojo, non daté, https://expedicionesapuertopiojo.wordpress.com/154-2/expediciones-en-proa/, page consultée le 11 septembre 2020 .

Florida, Richard L., Cities and the creative class, Londres, Routledge, 2005.

Gómez Schettini, Mariana et Zunino Singh, Dhan (2008); « La [re]valorización de la zona sur y su patrimonio histórico-cultural como recurso turístico ", in Hilda Herzer, (coord.), Con el corazón mirando al sur. Transformaciones en el sur de la ciudad de Buenos Aires, Buenos Aires, Espacio Editorial, p. 325-367.

Grésillon, Boris, «Ville et création artistique. Pour une autre approche de la géographie culturelle » Annales de Géographie, nº66-661, 2008, p. 179-198.

Gómez Schettini, Mariana, Almirón, Analía et González Bracco, Mercedes, « La cultura como recurso turístico de las ciudades. El caso de la patrimonialización del tango en Buenos Aires, Argentina », Estudios y Perspectivas en Turismo n²0, 2011, p. 1027-1046.

Goicoechea, María Eugenia, « ¿Desarrollo en el sur de Buenos Aires? Renovación urbana y valorización inmobiliaria », Bitácora Urbano Territorial, Vol. 28, n² 2, 2018, p. 9-16.

Golte, Melissa, « Fotoreportaje, Sinvergüenza! Intervenciones Urbanas Iberoamericanas », Anthropia 9, 2011, p. 43-53.

Guinard, Pauline et Morovich, Barbara, « Arts, mémoires et engagement au Drill Hall (Johannesburg) : l'invention d'un patrimoine incertain ", L'Information géographique, Vol. 81, 2017), p. 121-145.

Guinard, Pauline et Morovich, Barbara (coord.), « Villes, cultures et engagements », Journal des Anthropologues, $\mathrm{n}^{\circ}$ 162-163, 2020.

Herzer, Hilda (coord..) Barrios al sur. Renovación y pobreza en la Ciudad de Buenos Aires, Buenos Aires, Edición Café de las Ciudades, 2012.

Hidalgo, Rodrigo et Janoschka, Michael (eds.), La ciudad neoliberal: gentrificación y exclusión en Santiago de Chile, Buenos Aires, Ciudad de Mexico y Madrid, Santiago, Universidad Católica, 2014.

Hobsbawm, Eric et Ranger Thomas, L'invention de la tradition, Paris, Editions Amsterdam, 2006.Jeifetz, Nestor et Rodríguez, Maria-Carla. « La génesis del movimiento cooperativista autogestionario en la ciudad de Buenos Aires y la construcción de políticas de hábitat popular ", Revista Vivienda Popular, n 59, 2006, p. 43 - 58 
Lacarrieu, Mónica, « Que los conventillos no mueran: disputas por el espacio barrial », in Grillo, Oscar, Mónica, Lacarrieu et Raggio, Liliana, Políticas sociales y estrategias habitacionales, Buenos Aires, Espacio Editorial, 1995, p. 62-119.

Lacarrieu, Mónica « Mercados tradicionales" en los procesos de gentrificación / recualificación. Consensos, disputas y conflicto ", Alteridades, n 26 (51), 2016, p. 29-41.

Lacarrieu, Monica, Thomasz, Ana Gretel, Benza, Silvia, Laborde, Soledad, Diaz Marchi, Daniela, «Quand l'essentiel est visible pour les yeux. Multiculturalisme et patrimoine dans la ville de Buenos Aires ", in Caroline de Saint Pierre (coord.), La mise en jeu du patrimoine dans la configuration de la ville d'aujourd'hui, Presses Universitaires de Rennes, Paris, 2014, p. 147-161.

Landry, Charles et Bianchini, Franco, The Creative City, Londres, Demos, 1995.

La Retaguardia, « Gabriela Olguín, en medio de la polémica por la Feria de artesanías de San Telmo », Kaosenlared, 10 Février 2019, https://kaosenlared.net/argentina-gabriela-olguin-enmedio-de-la-polemica-por-la-feria-de-artesanias-de-san-telmo/\#, page consultée le 11 septembre 2020 .

Le Gallou, Aude, « Le street art entre valorisation informelle du territoire et logiques d'institutionnalisation », EchoGéo [En ligne], n 44, 2018.

Ley, David, «Artist, Aestheticisation and the Field of Gentrification », Urban Studies, $n^{\circ} 40,2003$, p. 2527-2544.

López-Morales, Ernesto, Bang Shin, Hyun et Lees, Loretta, « Latin American gentrifications », Urban Geography, n 37, 2016, p. 1091-1108

Morovich, Barbara, « Entre stigmates et mémoires : dynamiques paradoxales de la rénovation urbaine », Articulo - Journal of Urban Research, Special issue 5 | 2014.

Morovich, Barbara (dir.), Interroger le changement urbain, Editions de l'ENSAS, Strasbourg, 2017. Morovich, Barbara, Miroirs anthropologiques et changement urbain : qui participe à la transformation des quartiers populaires? Paris, L'Harmattan, 2017 (2).

Movimiento de ocupantes e inquilinos, « Historia », Movimiento de ocupantes e inquilinos, https:// moi.org.ar/historia/, page consultée le 10 septembre 2020.

Musse, Valeria, « San Telmo: luego de décadas de abandono, el edificio del ex Padelai se convirtió en sede de la Comuna 1 », La Nación, 4 Juin 2018, https://www.lanacion.com.ar/sociedad/santelmo-luego-de-decadas-de-abandono-el-edificio-del-ex-padelai-se-convirtio-en-sede-de-lacomuna-1-nid2140761, page consultée le 12 septembre 2020.

Olivier De Sardan, Jean-Pierre, « Le développement local comme champ politique local », Bulletin de l'APAD, n 6, Marseille, 1993, p. 11-18.

Paci, Julieta, « Ocupan de nuevo el ex Padelai », La Nación, 11 Mai 2012,

https://www.lanacion.com.ar/buenos-aires/ocupan-de-nuevo-el-ex-padelai-nid1472211/, page consultée le 12 septembre 2020.

Programa Recup Boca: Una carta de desarrollo social y urbano del barrio, Buenos Aires, Municipalidad de la Ciudad de Buenos Aires, 1988.

Plan de Manejo del Casco Histórico, Dirección General del Casco Histórico, Buenos Aires, 2015.

Prévôt-Schapira, Marie-France, «Buenos Aires, métropolisation et nouvel ordre politique ", Hérodote, $\mathrm{n}^{\circ}$ 101, 2001, p. 122-152. 
Rifkin, Jeremy, The Age of Access : The New Culture of Hypercapitalism, where All of Life is a Paid-for Experience, New York, Tarcher/Putnam, 2000.

Rodríguez, María Carla et Di Virgilio, María Mercedes, « A city for all? Public policy and resistance to gentrification in the southern neighborhoods of Buenos Aires ", Urban Geography n³7(8), 2016, p. 1215-1234.

Rozenberg, Guillaume (textes réunis et présentés par), La culture en débat, l'anthropologie en question, Les Carnets de Bérose, $\mathrm{n}^{\circ}$ 13, 2020.

Sánchez, Nora, «Ex Padelai por dentro: cómo quedó tras tres décadas de ocupación y conflicto », Clarín, 5 Janvier 2017, https://www.clarin.com/ciudades/ex-padelai-dentro-quedo-decadasocupacion-conflicto_0_HJ_uNZnSg.html, page consultée le 12 septembre 2020.

Santamaria, Marino, Projecto Calle Lanin, Buenos Aires, Ministerio de Cultura de la Ciudad de Buenos Aires, 2015.

Thomasz, Ana Gretel, « Los nuevos distritos creativos de la Ciudad de Buenos Aires: la conversión del barrio de La Boca en el "Distrito de las Artes" », Eure (Santiago), vol.42, n 126, 2016, p.123-144.

Thomasz, Ana Gretel, « Del Recup Boca al Distrito de las Artes: paradigmas opuestos de desarrollo local », Planeo no 31, 2017, p. 10-17.

Vivant, Elsa et Charmes, Éric, « La gentrification et ses pionniers : le rôle des artistes off en question ", Métropoles [En ligne], $n^{\circ}$ 3, 2008.

Vivant, Elsa Qu'est-ce que la ville créative?, PUF, Paris, 2009.

Zamant, Véronique, « Le paysage culturel, entre préservation et développement. Les enjeux institutionnels de la patrimonialisation du paysage de Rio de Janeiro ", L'Information géographique, Vol. 81, 2017, p. 94-120.

\section{NOTES}

1. Voir dossier du Journal des Anthropologues sur «Villes, cultures et engagements »(2020), coordonné par Pauline Guinard et l'auteure.

2. Cet article est écrit en marge d'une recherche effectuée lors de workshops franco-argentins (ENSA-Strasbourg, FADU-UBA et FADAU-Morón) dont j'étais responsable scientifique et que j'ai codirigés avec des collègues argentins entre 2015 et 2019.

3. Pour un bilan de ce concept : Nathalie Blanc et Marine Legrand, «Vers une recherche-création : Explorer la portée transformatrice des récits dans les relations au milieu de vie ", 2019, ACME 18(1) : 49-76.

4. Par «ville» de Buenos Aires, j'entends la Ciudad Autónoma de Buenos Aires, c'est-à-dire la capitale fédérale.

5. Je n'entends pas ici explorer la gentrification comme théorie générale, d'autres l'ont fait et depuis les années 1960, je me tiens ici plus particulièrement à des dynamiques de gentrification à Buenos Aires, tout en les inscrivant dans un contexte latino-américain plus large.

6. Selon María Carla Rodríguez et María Mercedes Di Virgilio (2016, p. 8) en 2004, $37.63 \%$ des investissements pour des infrastructures concernaient les quartiers sud et seulement $11.61 \%$ la partie nord de la capitale.

7. Toutes les citations en espagnol ont été traduites par l'auteure.

8. Porteño signifie « du port » et fait référence aux habitants de la capitale fédérale de Buenos Aires en général. 
9. La candidature du tango (d'Argentine et d'Uruguay) comme "Patrimonio Cultural Inmaterial de la Humanidad" a été approuvée par l'UNESCO en 2009.

10. Histoire du MOI sur le site officiel du mouvement.

11. CEuvre des architectes Juan-Antonio et Juan-Carlos Buschiazzo, le Padelai est construit à la fin du XIX ${ }^{\mathrm{e}}$ siècle.

12. Article du journal Clarín «Vuelven ocupar Padelai, piden viviendas ». Article de La Nación "Ocupan de nuevo el ex Padelai».

13. Article du Clarín «Ex Padelai por dentro: cómo quedó tras tres décadas de ocupación y conflicto".

14. Article de El Grito del Sur « Una reconversión con historia ».

15. Article de La Nación «San Telmo: luego de décadas de abandono, el edificio del ex Padelai se convirtió en sede de la Comuna 1».

16. Ibid.

17. De mantas, « couvertures », car ils posent leurs produits sur des couvertures.

18. Dans l'article «Gabriela Olguín, en medio de la polémica por la Feria de artesanías de San Telmo ", du médium alternatif Kaosenlared, la présidente de l'association El Adoquín, insiste, dans un entretien, sur le fait que les commerçants et les antiquaires ne sont pas les principaux coupables de la situation, mais sont eux aussi victimes de la même crise et du même projet de « ville excluante».

19. Article « Gian Paolo Minelli y el arte de lo imposible».

\section{RÉSUMÉS}

Cet article analyse des « arènes culturelles » dans les Quartiers Sud de Buenos Aires. Depuis 2008, l'implantation de clusters ou districts créatifs ou économiques accompagne un phénomène de gentrification. L'ambiguïté du concept de culture et ses usages admet des appropriations en défense d'enjeux différents, parfois divergents. Ce travail montre la vivacité de ces arènes, la patience de leurs acteurs, leur résistance, leur capacité à freiner le processus de gentrification, à travers des contestations à long terme. Trois exemples sont développés, à San Telmo, à La Boca et à Piedrabuena. Dans ces quartiers, des projets en lien ou en conflit avec les institutions, sont vecteur d'identité et de patrimonialisation et parfois agissent contre la stigmatisation au nom de l'art et de la culture.

This article analyzes «cultural arenas» in the Southern Neighborhoods of Buenos Aires. Since 2008, the establishment of creative or economic clusters has accompanied a phenomenon of gentrification. The ambiguity of the concept of culture and its uses allows appropriations in defense of different issues, sometimes divergent ones. This work focuses on the liveliness of these arenas, the patience of their actors, their resistance, their ability to slow down the process of gentrification, through long-term challenges. Three examples are developed: San Telmo, La Boca and Piedrabuena. In these neighborhoods, projects linked or in conflict with institutions, are vectors of identity and patrimonialization and sometimes act against stigma, in the name of art and culture.

Este artículo analiza algunas «arenas culturales» en los Barrios al Sur de Buenos Aires. Desde 2008, la implantación de clusters o distritos creativos o económicos acompaña un fenómeno de 
gentrificación. La ambigüedad del concepto de cultura y sus usos admite apropiaciones en defensa de intereses diferentes, a veces divergentes. El trabajo de investigación muestra la vivacidad de estas arenas, la paciencia de sus actores, su resistencia, su capacidad de frenar el proceso de gentrificación, a través de protestas a largo plazo. De manera más específica, se desarrollan tres ejemplos, en San Telmo, La Boca y Piedrabuena. En estos barrios, proyectos relacionados o en conflicto con las instituciones, son vectores de identidad y de patrimonialización y a veces actúan contra la estigmatización en nombre del arte y de la cultura.

\section{INDEX}

Mots-clés : Culture, art, patrimonialisation, Buenos Aires, changement urbain

Palabras claves : Cultura, arte, patrimonialización, Buenos Aires, cambio urbano

Keywords : Culture, art, patrimonialization, Buenos Aires, urban change

\section{AUTEUR}

\section{BARBARA MOROVICH}

Barbara Morovich est Maîtresse de conférences en anthropologie à l'École nationale supérieure d'architecture de Strasbourg, affiliée au laboratoire AMUP et présidente de l'Association Française des Anthropologues (AFA). Elle est progressivement passée d'une anthropologie des mouvements religieux (Kenya) à celle des émergences sociales et des transformations sociospatiales des quartiers populaires induites par les changements urbains en France (surtout Strasbourg), Argentine (Buenos-Aires) et plus récemment en Afrique du Sud (Johannesburg). 